\title{
Knowledge, Perception, and Barriers of Reporting of Nurses on Surveillance of Adverse Events Following Immunization in Zobamaekel, Eritrea
}

\author{
Michael Semere $^{1}$, LwamGhirmay ${ }^{1}$, Medhanie Weldegergis ${ }^{1}$, Aron Rezene ${ }^{2 *}$ \\ ${ }^{1}$ Asmara College of health sciences, School of Nursing, Eritrea \\ ${ }^{2}$ Department of Clinical Laboratory Science, Eritrea
}

*Corresponding Author:Aron Rezene, Department of Clinical Laboratory Science. Eritrea. Email: aronrezene19@gmail.com

\begin{abstract}
Background: vaccination programs contribute considerably to global health by providing protection against many important transmissible infections. However, careful investigation must be done following immunization so that to prevent adverse events resulting from immunization. So the knowledge and practice of AEFI in nurses is one of the mandatories that the system should overlook continuously.
\end{abstract}

Methodology: This descriptive quantitative cross-sectional study was conducted at health facilities in maekel zone, Eritrea, between January 2019 and June 2019. All the 33 immunisation giving health facilities in the zone were included. A total of 60 nurses were given the questionnaire and Data entry, cleaning and Analysis were done using IBM® SPSS version 22 package software. Results were summarised using frequency tables and pie charts.

Result: $25 \%(n=15)$ of the respondents had good knowledge towards AEFI surveillance. $73.3 \%(n=44)$ of the respondents had perception level between $50 \%$ and $74.99 \%$ on AEFI surveillance. $60 \%$ (n=36) had 0 to 4 barriers of reporting towards AEFI surveillance. Respondents aged between 36 to 50 years and male respondents had good knowledge levels on AEFI surveillance. In addition, there was a significant association between respondents' level of qualification and their perception on surveillance of AEFI. No significant association was found between respondents' characteristics and their barriers to reporting. In addition, no correlation was found in between the three dependent variables; Knowledge, perception and barriers to reporting.

Conclusion: Overall, majority of the respondents working in ZobaMaekel Health facilities had moderate and good knowledge levels and perception levels respectively on AEFI surveillance. Thus, information generated from this study might be valuable in informing policy review on immunization programs at the health facilities of Zoba-Maekel and enhance AEFI surveillance and consolidate the gains made in immunization coverage.

Keywords: Knowledge, Perception, Barriers, AEFI

\section{INTRODUCTION}

Immunization of infants and young children against serious infectious diseases is the most successful and cost-effective intervention in preventative health care. Moreover, vaccination programs contribute considerably to global health by providing protection against many important transmissible infections [1].

According to estimations made by the World Health Organization, approximately two million deaths among children under 5 years of age can be prevented annually through the use of existing vaccines [2]. In Eritrea, Expanded Program on Immunization (EPI) was launched in 1980. But, noticeable progress on the program development and delivery of immunization services was only possible after independence in 1991.

During the independence, immunization service was provided in 125 health facilities at static and in 45 outreach sites, and immunization coverage for fully immunized <1year children was $9.4 \%$. Since independence, the National Program on Immunization has made significant progress in developing and delivering of immunization services for children and women through routine 
immunization activities. However, careful investigation must be done following immunization so that to prevent adverse events resulting from immunization (MOH, Eritrea, EPI department, 2017) [3]. According to WHO AEFI is any untoward medical occurrence which occurs after immunization and which does not necessarily have a causal relationship with the usage of the vaccine and is classified in to into five main categories which are vaccine reactions, programme errors, coincidental events, injection reactions and unknown events [4].Adverse events in health care are believed to contribute for 44,000 to 98,000 accidental deaths and over one million excess injuries each year [5].The knowledge and practice of AEFI in nurses is one of the mandatories that the system should overlook continuously. In a study done in surveillance of AEFI in Zimbabwe, none of the 61 nurses interviewed could correctly define an AEFI and AEFI notification and investigation forms were available at 6 out of 18 health facilities $[6,7]$. But it is not only the perception and knowledge of AEFI needed; also a good practice of AEFI reports is highly recommended for nurses responsible with such programme [8]. This is because in a study done in Kenya, $45.3 \%$ of the respondents had good perception towards AEFI surveillance while $32.1 \%$ of the respondents had good practice towards AEFI surveillance [9].According to the national office of the vaccine pharma co vigilance department in Eritrea, more than 1500 nurses were given training on an operational AEFI surveillance in 2017 and yet less than 20 AEFI cases were reported. So this research article was made to examine the knowledge, perception, and barriers for reporting of nurses towards AEFI surveillance.

\section{MATERIALS AND METHODS}

\subsection{Study Setting and Population}

This descriptive quantitative cross-sectional study was conducted at health facilities in maekel zone, Eritrea, between January 2019 and June 2019. All the 33 immunisation giving health facilities in the zone were included. Out of which only one was non-governmental and the all rest were governmental. And from those all health service providers, 8 were found in Serejeka Subzone, 3 were found in Berik Subzone, 5 were found in Gala-nefhi Subzone, 3 were found in Northern east Asmara, 4 were found in Northern west Asmara, 3 were found in South east Asmara, and 7 were found in South west Asmara. Of all the health service providers, 1 was a Referral hospital (Orotta NRH; MCH department which gives vaccination to neonates), 3 were Community hospitals (EPI and $\mathrm{MCH}$ department), 6 were health centres and the rest 23 were health stations (EPI department).

\subsection{Data Collection}

Eligible nurses from each health facility were all enrolled in the study. A total of 60 nurses were given the questionnaire. Self-administered, adopted and self-made questionnaires were used for collecting data from consenting nurses. The questionnaire included specific questions on nurses, socio-demographic characteristics and their knowledge, perception, and barriers of reporting towards surveillance of adverse events following immunisation. In order to insure the efficacy and feasibility of the tool, the questionnaire was pretested in four health facilities of Debub zone. The four health facilities had similar characteristics to the health facilities in the study.

\subsection{Statistical Analysis}

Data entry, cleaning and Analysis were done using IBM® SPSS version 22 package software. Results were summarised using frequency tables and pie charts. Knowledge levels were assessed using a series of 15 questions on AEFI, its causes, management, diagnosis, prevention and reporting of AEFI. Each correct response was assigned a score of 1.0 and each incorrect response was allocated a score of 0.0 . Then the overall score was calculated for all the 15 knowledge responses for each individual. The questions with multiple correct responses were given 1.0 for each correct response and those with only one correct response were given a score of 1.0 for the whole question. The maximum expected score was 42. Respondents' knowledge score was described in terms of percentages and then was classified into Poor knowledge (0-49.99\%), Moderate knowledge (50-74.99\%) and Good knowledge (75-100\%) [9]. Perception towards AEFI surveillance was assessed using 10 statements on a 7-point Likert scale. Total perception score was taken as the percentage out of a hundred percent. Respondents' barriers of reporting were assessed using 14 close-ended questions. Those who responded "Yes" to the questions implying barriers and similarly, those who responded "No" to the questions implying a normal practice were give a score of 1.0. The respondents who responded "No" to the questions implying barriers and "Yes" to the questions implying a normal practice were given 
a score of 0.0 . Then a total score of 14 was calculated and was classified in to three groups; $0-4,5-9$, and $10-14$. Descriptive analysis was done using percentages for the categorical variables and mean/median with their corresponding measures of dispersion (as appropriate) after being checked for normality. Further more independent t-test and ANOVA were used to investigate the difference in scores of knowledge, perception and barriers to reporting of nurses on surveillance of AEFI and the selected independent variables. Moreover, correlation between the three dependent variables was checked using spearman's correlation. P-values less than 0.05 were rendered as significant throughout the study.

\subsection{Ethical Consideration}

Ethical approval was first given from ACHS research and post graduate office and ethical clearance committee of $\mathrm{MOH}$. Written informed consent was provided and signed by each respondent and was then used to gather data from

Table1: Socio-demographic characteristics of study respondents

\begin{tabular}{|c|c|c|}
\hline Variable & Frequency & Percent \\
\hline \multicolumn{3}{|l|}{ Age (years) } \\
\hline Mean (SD) & \multicolumn{2}{|l|}{$35.70( \pm 3.24)$} \\
\hline $21-35$ & 36 & 60 \\
\hline $36-50$ & 12 & 20 \\
\hline $51-63$ & 12 & 20 \\
\hline \multicolumn{3}{|l|}{ Gender } \\
\hline Male & 4 & 6.7 \\
\hline Female & 56 & 93.3 \\
\hline \multicolumn{3}{|l|}{ Level of Qualification } \\
\hline Degree & 2 & 3.3 \\
\hline Diploma & 17 & 28.3 \\
\hline Certificate & 41 & 68.3 \\
\hline \multicolumn{3}{|l|}{ Employer } \\
\hline Governmental & 58 & 96.7 \\
\hline Non-governmental & 2 & 3.3 \\
\hline \multicolumn{3}{|l|}{ Years of Experience } \\
\hline Mean (SD) & \multicolumn{2}{|l|}{$14.18( \pm 3.17)$} \\
\hline $1-10$ years & 37 & 61.7 \\
\hline $11-43$ years & 23 & 38.3 \\
\hline \multicolumn{3}{|l|}{ Service at the facility } \\
\hline Mean (SD) & \multicolumn{2}{|l|}{$4.67( \pm 1.81)$} \\
\hline $1-5$ years & 42 & 70 \\
\hline $6-15$ years & 18 & 30 \\
\hline \multicolumn{3}{|l|}{ Training in AEFI } \\
\hline Yes & 47 & 78.3 \\
\hline No & 13 & 21.7 \\
\hline \multicolumn{3}{|l|}{ Type of training } \\
\hline On job training & 10 & 21.3 \\
\hline Seminar or Workshop & 42 & 89.4 \\
\hline College or University class & 0 & 0 \\
\hline
\end{tabular}

each participant. Identity of the respondents was kept anonymous, but they received a unique study code based on their groups and they were given full right to drop from filling the given questionnaire at any time.

\section{Results}

\subsection{Base Line Characteristics of the Participants}

A total of 60 nurses were enrolled in the study. The mean (SD) age of the respondents was $35.70( \pm 3.24)$ years. Age distribution was as follows; $21-35$ years $(60 \%), 36-50$ years $(20 \%)$ and $51-63$ years $(20 \%)$. Almost all of the respondents were female $(93.3 \%)$. Most of the respondents $(68.3 \%)$ had a certificate level of nursing education compared to those with degree and diploma level (31.7\%). Respondents had $14.18( \pm 3.17)$ mean $(\mathrm{SD})$ years of experience as shown in Table 1. 
Knowledge, Perception, and Barriers of Reporting of Nurses on Surveillance of Adverse Events Following Immunization in Zobamaekel, Eritrea

\subsection{Knowledge, Perception and Barriers of Reporting on Surveillance of AEFI}

Most (85\%) respondents did not know the definition of AEFI. Almost all of the respondents (93.3\%) knew the causes of AEFI. Many (76.7\%) of the respondents knew the right routes of vaccine administration. Most (61.7\%) of the respondents knew who is responsible for receiving AEFI from health facilities. Many $(63.3 \%)$ of the respondents knew when AEFI investigation should be commenced as illustrated in Table 2.

Table2: knowledge levels of respondents on surveillance of AEFI

\begin{tabular}{|c|c|c|}
\hline Aspects of knowledge on AEFI surveillance & Frequency & Percent \\
\hline AEFI as a medical condition is not limited to vaccination only & 9 & 15 \\
\hline $\begin{array}{l}\text { AEFI can be caused by reconstituted vaccine stored longer than recommended } \\
\text { period; vaccine reaction; inappropriate route o0r injection technique; vaccines } \\
\text { stored beyond expiry date or contaminated vaccine diluents. }\end{array}$ & 56 & 93.3 \\
\hline BCG vaccine is given only through intradermal. & 46 & 76.7 \\
\hline Paracetamol and Ibuprofen is not used routinely to prevent immunization fever. & 23 & 38.3 \\
\hline \multicolumn{3}{|c|}{ Role of the personnel at the district level (sub-zone EPI focal person) on AEFI surveillance } \\
\hline AEFI detection & 34 & 56.7 \\
\hline AEFI investigation & 37 & 61.7 \\
\hline Case management & 42 & 70 \\
\hline Maintaining Records & 44 & 73.3 \\
\hline Notify the next level & 41 & 68.3 \\
\hline Training & 37 & 61.7 \\
\hline Imitate district level action & 24 & 40 \\
\hline \multicolumn{3}{|l|}{ Administration of adrenaline during post immunization anaphylaxis } \\
\hline Subcutaneous & 27 & 45 \\
\hline Intramuscular & 26 & 43.3 \\
\hline Subcutaneous and Intramuscular & 8 & 13.3 \\
\hline $\begin{array}{l}\text { During post-immunization anaphylaxis, Intramuscular administration of } \\
\text { adrenaline is more preferred than Subcutaneous administration because it has } \\
\text { increased absorption for the adrenaline. }\end{array}$ & 33 & 55 \\
\hline \multicolumn{3}{|l|}{ Positioning of a patient during anaphylaxis } \\
\hline Flat with legs raised & 23 & 38.3 \\
\hline Sleep on his/her side & 38 & 63.3 \\
\hline Sub-zone EPI focal person receives AEFI reports from facility nurse & 37 & 61.7 \\
\hline \multicolumn{3}{|l|}{ Aspects of immunization programme that AEFI investigation examine } \\
\hline Immunization error & 51 & 85 \\
\hline Vaccine related & 45 & 75 \\
\hline Handling (storage) error & 47 & 78.3 \\
\hline Investigation of an AEFI should be commenced within $24 \mathrm{hrs}$. & 38 & 63.3 \\
\hline All injection site abscesses should be reported & 57 & 95 \\
\hline $\begin{array}{l}\text { All injection site swelling and redness are not reported it depends on whether } \\
\text { the nearest join is reached or not. }\end{array}$ & 22 & 36.7 \\
\hline $\begin{array}{l}\text { Treatment of a coincidental illness falsely attributed as a vaccine reaction should } \\
\text { not be commenced before enlisting it for further expert investigation to ensure } \\
\text { that it was truly coincidental. }\end{array}$ & 32 & 53.3 \\
\hline \multicolumn{3}{|l|}{ Aim of immunization surveillance with respect to AEFI } \\
\hline Detect, correct and prevent programme errors & 52 & 86.7 \\
\hline Identify problems with vaccine lots or brand & 43 & 71.7 \\
\hline Address false blame from coincidental events & 33 & 55 \\
\hline $\begin{array}{l}\text { Maintain confidence by properly responding to concerns while increasing } \\
\text { awareness about vaccine risks }\end{array}$ & 40 & 66.7 \\
\hline $\begin{array}{l}\text { Estimate rates of occurrence on AEFI in the local population, compared with } \\
\text { trial and international data. }\end{array}$ & 36 & 60 \\
\hline
\end{tabular}

The overall mean (SD) knowledge score on causes of AEFI, identification, investigating, managing and reporting of AEFI was 27.7 $( \pm 1.33)$ out of a maximum 42 . Thus, $15(25 \%)$ of the respondents had good knowledge, $40(66.7 \%)$ had moderate knowledge whereas $5(8.3 \%)$ had poor knowledge on AEFI surveillance as shown in Figure 1.

$68.3 \%$ of the respondents believed that reporting an AEFI would make them feel guilty about 
having caused harm and be responsible for the event. Few (13.3\%) of the respondents believed that investigation of an AEFI should be done by clinical officers or doctors and not nurses. Few (15\%) respondents believe that the process of reporting AEFI is long and tedious. However, almost all (95\%) of the respondents feel that nurses play a vital role in diagnosing, reporting, investigating and managing AEFI. Most importantly, majority of the respondents $(98.4 \%)$ were ready to learn more about AEFI surveillance as shown in Table 3.

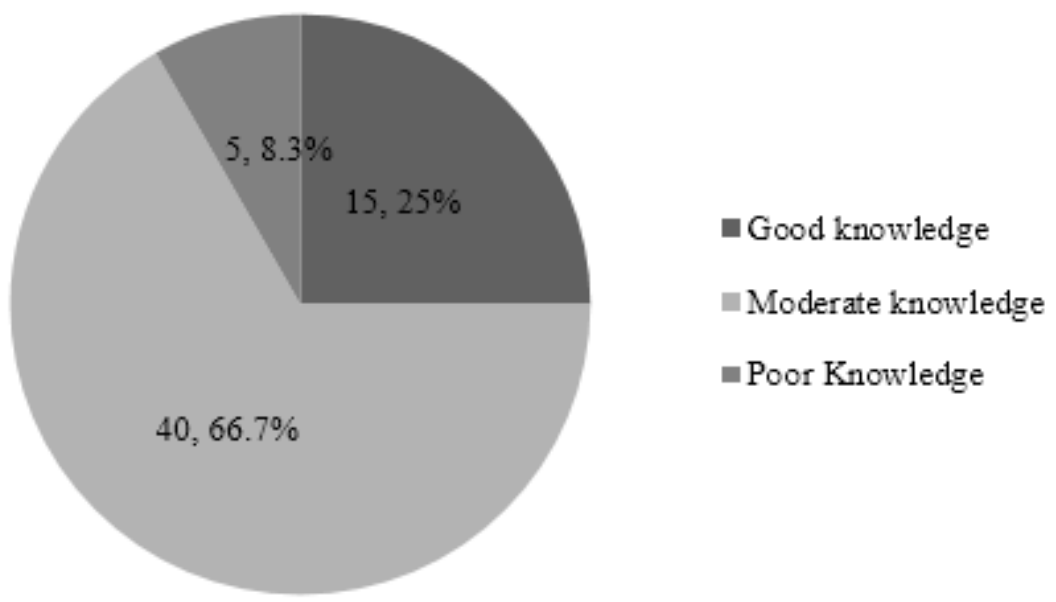

Figure1: Proportion of nurses with Good, Moderate and Poor knowledge on AEFI surveillance

Table3: Perception of respondents on surveillance of AEFI

\begin{tabular}{|c|c|c|c|c|c|}
\hline $\begin{array}{l}\begin{array}{l}\text { Perception on surveillance of AEFI } \\
n=60\end{array}\end{array}$ & $\begin{array}{l}\text { Strongly } \\
\text { Agree } \\
\mathrm{N}(\%)\end{array}$ & $\begin{array}{l}\text { Agree } \\
\mathbf{N}(\%)\end{array}$ & $\begin{array}{l}\text { Neutral } \\
\mathbf{N}(\%)\end{array}$ & $\begin{array}{l}\text { Disagree } \\
\mathbf{N}(\%)\end{array}$ & $\begin{array}{l}\text { Strongly } \\
\text { Disagree } \\
\mathbf{N}(\%) \\
\end{array}$ \\
\hline $\begin{array}{l}\text { Reporting an AEFI, such as injection } \\
\text { abscess, will make me feel guilty } \\
\text { about having caused harm and be } \\
\text { responsible for the event. }\end{array}$ & $14(23.3 \%)$ & $27(45 \%)$ & $2(3.3 \%)$ & $11(18.3 \%)$ & $\begin{array}{l}6 \\
(10 \%)\end{array}$ \\
\hline $\begin{array}{l}\text { Investigation of adverse events } \\
\text { following immunization should be } \\
\text { done by clinical officers or doctors and } \\
\text { not nurses }\end{array}$ & $\begin{array}{l}2 \\
(3.3 \%)\end{array}$ & $\begin{array}{l}6 \\
(10 \%)\end{array}$ & $\begin{array}{l}0 \\
(0 \%)\end{array}$ & $\begin{array}{l}33 \\
(55 \%)\end{array}$ & $19(31.7 \%)$ \\
\hline $\begin{array}{l}\text { Poor monitoring of AEFI can cause } \\
\text { reduction of immunization coverage }\end{array}$ & $25(41.7 \%)$ & $30(50 \%)$ & $\begin{array}{l}0 \\
(0 \%)\end{array}$ & $\begin{array}{l}4 \\
(6.7 \%)\end{array}$ & $\begin{array}{l}1 \\
(1.7 \%)\end{array}$ \\
\hline $\begin{array}{l}\text { The process of reporting an AEFI is } \\
\text { long and tedious }\end{array}$ & $\begin{array}{l}2 \\
(3.3 \%)\end{array}$ & $7(11.7 \%)$ & $\begin{array}{l}3 \\
(5 \%)\end{array}$ & $\begin{array}{l}33 \\
(55 \%)\end{array}$ & $\begin{array}{l}15 \\
(25 \%)\end{array}$ \\
\hline $\begin{array}{l}\text { Reporting and investigating suspected } \\
\text { AEFI is none of my business }\end{array}$ & $\begin{array}{l}1 \\
(1.7 \%)\end{array}$ & $\begin{array}{l}1 \\
(1.7 \%)\end{array}$ & $\begin{array}{l}0 \\
(0 \%)\end{array}$ & $\begin{array}{l}30 \\
(50 \%)\end{array}$ & $\begin{array}{l}28 \\
(46.7 \%)\end{array}$ \\
\hline $\begin{array}{l}\text { Even if adverse events are reported to } \\
\text { sub-zone EPI focal person, no } \\
\text { feedback is send back to the facility } \\
\text { that reported the event }\end{array}$ & $\begin{array}{l}1 \\
(1.7 \%)\end{array}$ & $\begin{array}{l}16 \\
(26.7 \%)\end{array}$ & $7(11.7 \%)$ & $20(33.3 \%)$ & $16(26.7 \%)$ \\
\hline $\begin{array}{l}\text { Enhancing surveillance of AEFI can } \\
\text { help build public trust in our } \\
\text { immunization programme }\end{array}$ & $\begin{array}{l}30 \\
(50 \%)\end{array}$ & $\begin{array}{l}29 \\
(48.3 \%)\end{array}$ & $\begin{array}{l}0 \\
(0 \%)\end{array}$ & $\begin{array}{l}1 \\
(1.7 \%)\end{array}$ & $\begin{array}{l}0 \\
(0 \%)\end{array}$ \\
\hline $\begin{array}{l}\text { Nurses play a vital role in diagnosing, } \\
\text { reporting, investigating and managing } \\
\text { Adverse Events Following } \\
\text { Immunization (AEFI }\end{array}$ & $29(48.3 \%)$ & $\begin{array}{l}28 \\
(46.7 \%)\end{array}$ & $\begin{array}{l}0 \\
(0 \%)\end{array}$ & $\begin{array}{l}3 \\
(5 \%)\end{array}$ & $\begin{array}{l}0 \\
(0 \%)\end{array}$ \\
\hline $\begin{array}{l}\text { I am ready to learn more about how to } \\
\text { diagnose, report, investigate and } \\
\text { manage Adverse Events Following } \\
\text { Immunization (AEFI) }\end{array}$ & $31(51.7 \%)$ & $\begin{array}{l}28 \\
(46.7 \%)\end{array}$ & $\begin{array}{l}0 \\
(0 \%)\end{array}$ & $\begin{array}{l}1 \\
(1.7 \%)\end{array}$ & $\begin{array}{l}0 \\
(0 \%)\end{array}$ \\
\hline $\begin{array}{l}\text { Every nurse working at a health } \\
\text { facility should know about AEFI }\end{array}$ & $35(58.3 \%)$ & $\begin{array}{l}25 \\
(41.7 \%)\end{array}$ & $\begin{array}{l}0 \\
(0 \%)\end{array}$ & $\begin{array}{l}0 \\
(0 \%)\end{array}$ & $\begin{array}{l}0 \\
(0 \%)\end{array}$ \\
\hline
\end{tabular}


Total perception score was taken as the percentage out of a maximum hundred percent. And $26.7 \%$ of the respondents scored less than fifty percent. Most of the respondents (73.3\%) scored between $50 \%$ and $74.99 \%$. None of the respondents $(0 \%, \mathrm{n}=0)$ scored between $75 \%$ and $100 \%$ as shown in Figure 2.

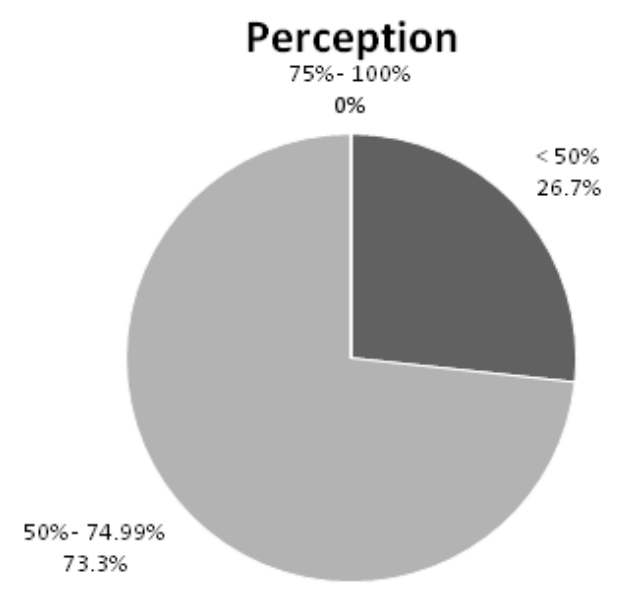

Figure2: proportion of respondents with $75 \%$ to $100 \%$ perception score, $50 \%$ to $74.99 \%$ perception score and less than $50 \%$ perception score.

Most of the respondents (65\%) reported that they have observed an AEFI. Majority (98.3\%) of the respondents knew that there is an AEFI reporting procedure. And almost all of the respondents (96.7\%) had adequate AEFI reporting forms available at their health facilities. Some (13.3\%) of the respondents had to leave reporting an AEFI at some point in their experience because they could not find reporting forms. Few of the respondents (6.7\%) have missed reporting an AEFI because they did not have time. Many of the respondents $(58.3 \%)$ reported that they do not think reporting an AEFI can make them liable. And most of the respondents (76.7\%) believed that you should report an AEFI even if you are not interested to report as shown in Table 4.

Table4: Barriers of reporting of nurses on surveillance of AEFI

\begin{tabular}{|l|l|l|}
\hline Questions & $\begin{array}{l}\text { Yes } \\
\text { N (\%) }\end{array}$ & $\begin{array}{l}\text { No } \\
\text { N }(\%)\end{array}$ \\
\hline Have you ever observed an AEFI? & $39(65 \%)$ & $21(35 \%)$ \\
\hline Is there an AEFI reporting procedure? & $59(98.3 \%)$ & $\begin{array}{l}1 \\
(1.7 \%)\end{array}$ \\
\hline Do you have adequate AEFI reporting forms available at your health facility? & $58(96.7 \%)$ & $\begin{array}{l}2 \\
(3.3 \%)\end{array}$ \\
\hline $\begin{array}{l}\text { Have you ever failed to report an AEFI case because you could not find an } \\
\text { AEFI reporting form? }\end{array}$ & $8(13.3 \%)$ & $52(86.7 \%)$ \\
\hline If you are not interested to report an AEFI case, you should leave it. & $14(23.3 \%)$ & $46(76.7 \%)$ \\
\hline Do you think reporting an AEFI case can make you liable? & $25(41.7 \%)$ & $35(58.3 \%)$ \\
\hline $\begin{array}{l}\text { Any event which occurred following immunization but you think is not related } \\
\text { to immunization should not be reported. }\end{array}$ & $28(46.7 \%)$ & $32(53.3 \%)$ \\
\hline $\begin{array}{l}\text { You should not report an event caused after vaccination if you are not confident } \\
\text { about the diagnosis. }\end{array}$ & $20(33.3 \%)$ & $40(66.7 \%)$ \\
\hline Have you ever missed reporting an AEFI because you did not have time? & $4(6.7 \%)$ & $56(93.3 \%)$ \\
\hline $\begin{array}{l}\text { Should you report an anaphylactic reaction that occurred 24hrs after } \\
\text { vaccination of MMR? }\end{array}$ & $43(71.7 \%)$ & $17(28.3 \%)$ \\
\hline $\begin{array}{l}\text { A child who developed injection site abscess after being vaccinated with DPT } \\
\text { vaccine in another health facility was brought to you for treatment. You should } \\
\text { not report this AEFI case because you did not vaccinate the child. }\end{array}$ & $28(46.7 \%)$ & $32(53.3 \%)$ \\
\hline Any AEFI case that concerns a parent or caregiver should be reported. & $39(65 \%)$ & $21(35 \%)$ \\
\hline A minor AEFI case must be reported. & $33(55 \%)$ & $27(45 \%)$ \\
\hline $\begin{array}{l}\text { It is okay to postpone reporting an AEFI case which came to your attention and } \\
\text { report it later. }\end{array}$ & $15(25 \%)$ & $45(75 \%)$ \\
\hline
\end{tabular}


A total score of 14 was calculated, each for one barrier to reporting and was classified in to three groups; $(0-4),(5-9)$, and $(10-14)$. Most (60\%) of the respondents had $0-4$ barriers. Some
(38.3\%) respondents had $5-9$ barriers. And only one respondent $(1.7 \%)$ had $10-14$ barriers as shown in Figure 3.

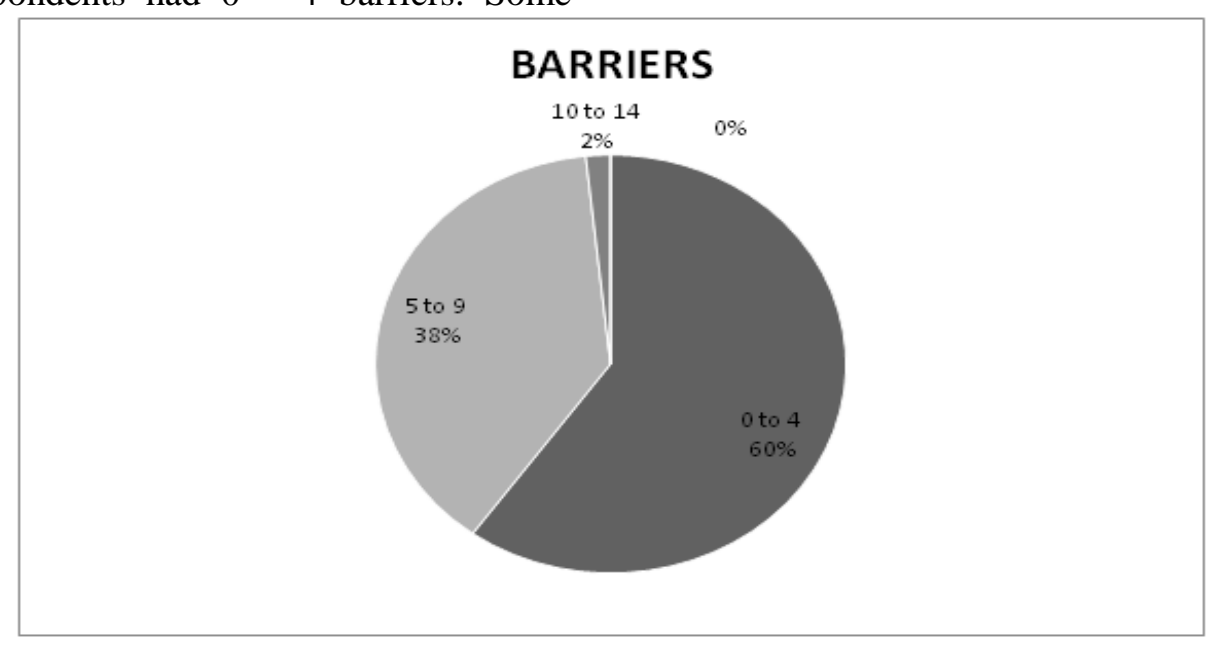

Figure3: proportion of respondents with $0-4$ barriers, $5-9$ barriers and $10-14$ barriers.

Association of Socio Demographic Characteristics and Knowledge, Perception and Barriers of Reporting on Surveillance of AEFI

Males ( $M=80.36, S D=14.20)$ were found to have significantly higher knowledge level as compared to females $(\mathrm{M}=64.92, \mathrm{SD}=11.56)(\mathrm{t}=-$ $2.55, p=0.014)$. No significant difference in level of knowledge was obtained between nurses with more years of experience and those with less years of experience $(\mathrm{t}=-1.82, p$-value $=0.071)$.

Moreover, the level of knowledge was not significantly different between those who took previous AEFI training $(\mathrm{M}=66.72, \mathrm{SD}=12.51)$ and those who do not $(\mathrm{M}=63.19, \mathrm{SD}=11.28)$ $(\mathrm{t}=0.92, p=0.362)$ as shown in Table5.

Table5: Association between knowledge and respondents' characteristics.

\begin{tabular}{|c|c|c|c|}
\hline Variable & Mean (SD) & t/F statistic & $P$-value \\
\hline \multicolumn{4}{|l|}{ Age } \\
\hline $21-35$ & $63.76(11.51)$ & 4.14 & 0.021 \\
\hline $36-50$ & $74.6(10.62)$ & & \\
\hline $51-63$ & $63.89(12.96)$ & & \\
\hline \multicolumn{4}{|l|}{ Gender } \\
\hline Male & $80.36(14.20)$ & -2.55 & 0.014 \\
\hline Female & $64.92(11.56)$ & & \\
\hline \multicolumn{4}{|c|}{ Level of Qualification } \\
\hline Diploma & $63.17(10.82)$ & 1.27 & 0.21 \\
\hline Certificate & $67.6(12.75)$ & & \\
\hline \multicolumn{4}{|c|}{ Years of experience } \\
\hline $1-10$ years & $63.71(11.36)$ & -1.82 & 0.071 \\
\hline $11-43$ years & $69.57(13)$ & & \\
\hline \multicolumn{4}{|c|}{ Service at the facility } \\
\hline $1-5$ years & $65.76(10.87)$ & -0.19 & 0.854 \\
\hline $6-15$ years & $66.4(15.34)$ & & \\
\hline \multicolumn{4}{|c|}{ Training in AEFI } \\
\hline Yes & $66.72(12.51)$ & 0.92 & 0.362 \\
\hline No & $63.19(11.28)$ & & \\
\hline
\end{tabular}

Table5.1: Least Significant Difference (LSD)-Post hoc of Age

\begin{tabular}{|l|l|l|l|l|l|}
\hline \multicolumn{2}{|c|}{ Age Category } & \multicolumn{1}{c|}{ Mean Difference } & \multicolumn{1}{c|}{$\boldsymbol{p}$-value } & \multicolumn{2}{c|}{ 95\% Confidence Interval } \\
\hline 21 to 35 & 36 to 50 & -10.02 & 0.007 & -18.62 & -3.08 \\
\hline & 51 to 63 & -0.13 & 0.973 & -7.90 & 7.64 \\
\hline 36 to 50 & 51 to 63 & 10.71 & 0.028 & 1.20 & 20.23 \\
\hline
\end{tabular}


Knowledge, Perception, and Barriers of Reporting of Nurses on Surveillance of Adverse Events Following Immunization in Zobamaekel, Eritrea

A significant difference was found between respondents' perception and the two categories of level of qualification. Nurses at certificate level were likely to have higher perception $(\mathrm{M}=41$, $\mathrm{SD}=52.98)$ as compared to nurses at diploma level $(\mathrm{M}=17, \mathrm{SD}=49.88) \quad(\mathrm{t}=2.117, p=0.039)$. There was no significant difference between respondents' perception and the two categories of

Table6: Association between perception and respondents' characteristics.

\begin{tabular}{|c|c|c|c|}
\hline Variable & Mean (SD) & t/F statistic & $P$-value \\
\hline \multicolumn{4}{|l|}{ Age } \\
\hline $21-35$ & $53.17(5.05)$ & & \\
\hline $36-50$ & $50(5.78)$ & 1.66 & 0.199 \\
\hline $51-63$ & $52(5.33)$ & & \\
\hline \multicolumn{4}{|l|}{ Gender } \\
\hline Male & $53(2.58)$ & & \\
\hline Female & $52.25(5.46)$ & -0.271 & 0.787 \\
\hline \multicolumn{4}{|c|}{ Level of Qualification } \\
\hline Diploma & $17(49.88)$ & 2.117 & 0.039 \\
\hline Certificate & $41(52.98)$ & & \\
\hline \multicolumn{4}{|c|}{ Years of experience } \\
\hline $1-10$ years & $53.03(5.05)$ & 1.321 & 0.193 \\
\hline $11-43$ years & $51.13(5.62)$ & & \\
\hline \multicolumn{4}{|c|}{ Service at the facility } \\
\hline $1-5$ years & $52.33(5.28)$ & 0.074 & 0.942 \\
\hline $6-15$ years & $52.22(5.53)$ & & \\
\hline \multicolumn{4}{|c|}{ Training in AEFI } \\
\hline Yes & $50.77(5.75)$ & -1.108 & 0.282 \\
\hline No & $52.72(5.17)$ & & \\
\hline
\end{tabular}

There was no significant difference between respondents' barriers of reporting and the two categories of level of qualification $(\mathrm{Mw}=324.5$, $\mathrm{Z}=-0.417 p=0.68$ ). Similarly, there was no significant difference between respondents' barriers of reporting and the two categories of total years of experience $(\mathrm{t}=1.321, \quad p$ value $=0.193$ ). Moreover, there was no significant association in respondents' perception between those who took previous AEFI training $(\mathrm{M}=50.77, \mathrm{SD}=5.75)$ and those who do not $(\mathrm{M}=52.72, \quad \mathrm{SD}=5.17) \quad(\mathrm{t}=-1.108, \quad p=0.282) \quad$ as shown in Table 6.

Table7: Association between barriers of reporting and respondents' characteristics.

\begin{tabular}{|c|c|c|c|}
\hline Variable & Median (IQR) & Mann - Whitney (Z) / $X^{2}$ & $P$-value \\
\hline \multicolumn{4}{|l|}{ Age } \\
\hline $21-35$ & $4(2)$ & $X^{2}=5.85$ & 0.054 \\
\hline $36-50$ & $2.5(3)$ & & \\
\hline $51-63$ & $5(3)$ & & \\
\hline \multicolumn{4}{|l|}{ Gender } \\
\hline Male & $3(3)$ & $90.0(-0.66)$ & 0.508 \\
\hline Female & $4(2)$ & & \\
\hline \multicolumn{4}{|c|}{ Level of Qualification } \\
\hline Diploma & $3(3)$ & $324.5(-0.417)$ & 0.68 \\
\hline Certificate & $4(2)$ & & \\
\hline \multicolumn{4}{|c|}{ Years of experience } \\
\hline $1-10$ years & $4(2)$ & $418.0(-0.12)$ & 0.91 \\
\hline $11-43$ years & $4(3)$ & & \\
\hline \multicolumn{4}{|c|}{ Service at the facility } \\
\hline $1-5$ years & $4(2)$ & $354.0(-0.39)$ & 0.69 \\
\hline $6-15$ years & $4(3)$ & & \\
\hline \multicolumn{4}{|c|}{ Training in AEFI } \\
\hline Yes & $4(2)$ & $270.5(-0.64)$ & 0.523 \\
\hline No & $4(3)$ & & \\
\hline
\end{tabular}




\subsection{Correlation between Respondents' Knowledge, Perception and Barriers of Reporting on Surveillance of AEFI}

There was no significant correlation between nurses' knowledge and perception ( $\mathrm{r}=-0.025$, $\mathrm{p}=0.846)$. Similarly, no correlation was found among nurses' knowledge level and their reporting barriers $(\mathrm{r}=-0.232, \quad p=0.073)$. Moreover, no correlation was found between nurses reporting barriers and perception $(\mathrm{r}=-$ $0.060, p=0.648$ ) as shown in Table 8 .

Table8: correlation between respondents' knowledge, perception and barriers of reporting

\begin{tabular}{|l|l|l|l|}
\hline \multicolumn{5}{|c|}{ Correlation between knowledge, perception and barriers of reporting of nurses on surveillance of } \\
& \multicolumn{1}{|c|}{ Barrier } & \multicolumn{1}{c|}{ Perception } & \multicolumn{1}{c|}{ Knowledge } \\
\hline Barriers & 1 & $-0.060(0.648)$ & $-0.232(0.073)$ \\
\hline Perception & - & 1 & $-0.025(0.846)$ \\
\hline Knowledge & - & - & 1 \\
\hline
\end{tabular}

\section{DISCUSSION}

Nurses are key players in the immunization programmes and their knowledge, perception and practice towards surveillance of AEFI influences the quality and safety of the vaccination services besides monitoring and surveillance of AEFI [10]. According to the findings of this study, it could be inferred that majority of the nurses across central zone, Eritrea have high level of knowledge. This can be attributed to the good knowledge that those participants have gained on the formal training. These findings are consistent with the high knowledge level on surveillance of AEFI recorded by nurses in USA [11]. However, the findings of this study differ from previous studies reporting low knowledge levels on AEFI surveillance in China [12] and Kenya [9]. Moreover, only few (15\%) of the respondents knew the exact definition of AEFI which is given by the WHO. Many $(76.7 \%)$ of the respondents knew the right routes of vaccine administration. Even though majority of the respondents knew the cause of AEFI, many of the respondents did not know how to treat AEFI cases. For instance, only a small portion of the respondents knew how adrenaline is given in the emergency management of anaphylaxis following vaccination and how to position a baby during anaphylactic reaction. This observation contrasts with previous studies in Sri-Lanka indicating that a majority of respondents in an AEFI survey knew of adrenaline usage in the management of vaccine-induced anaphylactic reactions [13].

Association Analyses indicated that knowledge level of the respondents in this study on AEFI increased on the age category 36 to 50 of the nurses. However, these results are different from the previous studies in Kenya indicating that knowledge level of the respondents increased with their age and experience can be explained in part by accumulation of knowledge with increasing years of working experience [9]. Despite the fact that majority of the nurses were female, male nurses were more knowledgeable than their female counterparts. Academic qualifications did not influence the knowledge of the nurses towards AEFI surveillance, because both diploma and certificate nurses attained the same level of knowledge. Similarly, the results of this study indicated that there was no association between knowledge and previous training on AEFI. However, compared to other studies, majority of the nurses in this study had previous training in surveillance of AEFI. The $78.2 \%$ of participants in this study who had received prior training in AEFI surveillance were higher than the $48.2 \%$ recorded in Kenya [9] and 6\% recorded in Zimbabwe [7].

Almost all of the respondents stated that reduction of immunisation coverage can be caused as a result of poor AEFI monitoring. Furthermore, a high proportion of respondents believed that enhancing AEFI surveillance could help build public trust in immunization programme. Moreover, a high proportion of respondents showed high interest to learn more about AEFI surveillance. Although 95\% of the respondents believed that nurses play a vital role in AEFI surveillance, 5\% thought it was the responsibility of doctors and clinical officers. This finding is similar to a study in Kenya where three quarters of the respondents believed that nurses play a vital role in AEFI surveillance, but more than one third thought it was the responsibility of doctors and clinical officers [9]. Even though the proportion of nurses in our study who said investigation of adverse events following immunization should be done only by clinical officers or doctors is very low, $5 \%$, it still emphasizes the need for immunization managers to sensitize nurses on their role in AEFI surveillance. And since more than half of the 
respondents believed that reporting AEFI could lead to personal consequences, there is need to reassure nurses that reporting is not meant to be punitive or to apportion blame. The findings of our study showed no association between perception and previous training in AEFI surveillance and this was different from the findings of a study done in Kenya which showed a strong association $(P<0.0001)$ between perception and previous training in AEFI surveillance [9].

Despite the notion that having a higher level of qualification in nursing education increases the likelihood of having positive perception towards AEFI surveillance, our findings in this study indicated that nurses with certificate level of qualification were found to have positive perception as compared to those at diploma level. However, this finding differs from studies done in United Emirates and where no difference on perception was observed between nurses with degree and diploma nursing education [14] and from a study done in Kenya where having a degree in nursing education increased the likelihood of having good perception towards AEFI surveillance [9]. On the contrary, our findings indicated that no association was established between perception and other sociodemographic variables under study. There was also no association between age and perception towards AEFI. In a study done in United Emirates, association between age and perception was noted yet similar perception levels were observed across the different ages of the nurses [14]. Most participants (65\%) reported seeing or being involved in the care of children with a suspected AEFI, in their current or previous workplace. These findings were different from a study done in Albania where the main reason for not reporting was because a respondent thought he or she had not observed an AEFI (44.1\%) [15].

Moreover, in our study $98.3 \%$ of the respondents were aware that there is an AEFI reporting procedure which was different to a study done in Australia where few participants were aware of both local and national reporting processes [16]. Majority of the respondents in this study had adequate AEFI reporting forms available at their health facility, as a result fewer (13.3\%) of the respondents failed to report an AEFI because they could not find an AEFI reporting form. These findings were similar to the findings that a study in Kenya found a higher proportion $(44.5 \%)$ of respondents in their study had ever seen an AEFI reporting and investigation form [9] and different to what a study in Nigeria found where only twenty six percent of the nurses had ever seen the reporting form [17]. Even though majority of the respondents in our study knew that all serious AEFIs must be reported, some claimed that a minor AEFI case must not be reported which is contrary to the fact, minor AEFI should be reported but in consideration with the factors that increase its severity. This was different Compared to the study in United States, where most respondents did not know reportable post-immunization adverse events [11]. Majority (71.7\%) of the respondents reported that an anaphylactic reaction that occurred $24 \mathrm{hrs}$ after vaccination should be reported. This was different to a study done in Australia [16] where there was conflicting views as to which events ought to be reported.

Even though we have found more proportion of our nurses know which AEFIs to report and not to report, the few proportion of our nurses necessitate for the need of giving education regarding what are the reportable AEFIs. In this study, majority (66\%) of the respondents reported that they should not report an event caused after vaccination if they are not confident about the diagnosis. Here the national EPI sector should take notice that education on formulating diagnosis to a suspected AEFI should be given to the nurses. We found that many of the respondents $(46.7 \%)$ reported they should not report an AEFI case because they did not vaccinate the child themselves. This results in decreased reporting rates of reportable AEFIs and affects the surveillance system negatively causing a lesser occurrence of AEFI.

This study found no association between all the socio-demographic characteristics of the nurses and their availability of barriers to reporting. This was different to the findings in Kenya [9] where Nurses with previous training in AEFI were 6 times more likely to have good practices on AEFI surveillance. This study discovered no correlation between knowledge, perception and reporting barriers of nurses towards AEFI surveillance. This was different to a study done in Kenya [9] which found as the knowledge and perception of nurses on AEFI surveillance increases, their practice on AEFI surveillance increases. A similar trend was observed by [14] on reporting of adverse drug reactions. The low AEFI reporting rate, less than 20 AEFI cases were reported in 2017, in this study was surprising since majority of them were 
knowledgeable on which AEFI cases required reporting.

\section{CONCLUSION}

Overall, majority of the respondents working Zoba-Maekel Health facilities had good and moderate knowledge levels on AEFI surveillance. The overall perception level on AEFI surveillance amongst respondents working in Zoba-Maekel Health facilities was on the category between $50 \%$ and $74.99 \%$ (73\% of the respondents). Therefore, it can be inferred that perception level of the nurses on this study was good. Some respondents believed they would feel guilty and feared personal consequences on reporting an AEFI. In addition some perceived it was not their responsibility to carry out AEFI surveillance. The overall score of the respondents on reporting barriers of AEFI was on the category 0 to 4 barriers ( $60 \%$ of the respondents). Majority of the respondents reported that they have adequate AEFI reporting and investigation forms available. Few of them believed that you should leave reporting an AEFI if you are not interested. Some of the believed that reporting an AEFI case can make them liable. Formal education to Nurses should be introduced during their college or university years.

\section{ACKNOWLEDGMENT}

Our greatest appreciation goes to our statistician Mr. Eyasu Habte and our advisor Mr. Okbamichael Tekle for their dedication, constant availability, patience and thorough guidance. In addition, we thank the nurses and other staff working at Health Centres of ZobaMaekel for their immense participation and co-operation during data collection.

\section{REFERENCES}

[1] Buttery, J., Hazel, J., Clothier, C., Crawford, N.\&Kempe. (2011). Surveillance Of Adverse Events Following Immunization: The Model Of SAEFVIC, Victoria. Communicable Diseases Intelligence, Volume 35 (4).

[2] Arístegui J, Usonis V, Coovadia H, Riedemann S, Win KM, Gatchalian S, Bock HL. Facilitating The WHO Expanded Program Of Immunization: The Clinical Profile Of A Combined Diphtheria, Tetanus, Pertussis, Hepatitis B And Haemophilus Influenzae Type B Vaccine. Int J Infect Dis. 2003; 7(2):143-51.

[3] Ministry Of Health, Eritrea (2017), National EPI Department, Comprehensive Multi-Year Plan (2017-2021)

[4] Guidelines For Managers Of Immunization Programmes On Reporting And Investigating
Adverse Events Following Immunization Immunization Focus World Health Organization Regional Office For The Western Pacific Manila. 1999

[5] Weingart SN, Wilson RM, Gibberd RW, Harrison B. Epidemiology Of Medical Error. Bmj 2000; 320(7237):774-7.

[6] Manoochehrkarami Et.Al Adverse Events Following Immunization With Pentavalent Vaccine: Experiences Of Newly Introduced Vaccine In Iran, BMC Immunology (2017) 18:42 DOI 10.1186/S12865-017-0226-8

[7] Muchekeza M, Chimusoro A, Nomaguguncube, Kufakwanguzvarova W Pomerai2 (2014) Adverse Events Following Immunisation (AEFI) Surveillance In Kwekwe District, Midlands Province, Zimbabwe, 2009-2010. J Vaccines Vaccin 5: 232. Doi: 10.4172/ 21577560.1000232

[8] Awada Sanaa Et.Al Awareness And Perception Of National Pharmacovigilance Center Among Lebanese Medical Staff, J Pharmacovigilance 2016, 4:1 Http://Dx.Doi.Org/10.4172/23296887. 1000199

[9] Wanjala CM. Knowledge, Perception And Practice Of Nurses On Surveillance Of Adverse Event Following Childhood Immunization In Nairobi County, Kenya. Mph Thesis. Kenyatta University; 2014.

[10] Chopra, D., Rehan, H., \& Kumar, S. (2012). Comparison of Knowledge, Attitude And Practices Of Resident Doctors And Nurses On Adverse Drug Reaction Monitoring And Reporting In A Tertiary Care Hospital. Indian Journal Of Pharmacology, 44(6), 699-703.

[11] Mcneil, M., Li, R., Pickering S., Real T., Smith P., Pemberton, M. (2013). Who Is Unlikely To Report Adverse Events After Vaccinations To The Vaccine Adverse Event Reporting System (VAERS)? Vaccine, 13(24), 2673-2679).

[12] Li, Z., Xu, A., Song, L. (2012). Investigation On Knowledge, Attitude And Practice (KAP) About Adverse Events Following Immunization (AEFI) Among Staff On Immunization Programme In Shandong Province, China. Chinese Journal of Vaccines And Immunization.

[13] Ministry Of Health, Sri Lanka (2012). National Guidelines On Immunization Safety Surveillance: Surveillance Of Adverse Events Following Immunization

[14] Lisha, J., Arifulla, M., Cheriathu, J., Sreedharan, J. (2012). Reporting Of Adverse Drug Reactions: An Exploratory Study Among Nurses In A Teaching Hospital, Ajman, United Arab Emirates. Journal Of Pharmaceutical Sciences, 20(1), 44.

[15] Inside Mehmeti, Eridanelaj, Artansimaku, Eugena Tomini, Silva Bino. Knowledge, 
Knowledge, Perception, and Barriers of Reporting of Nurses on Surveillance of Adverse Events Following Immunization in Zobamaekel, Eritrea

Practice And Approaches Of Health Professionals To Adverse Events Following Immunization And Their Reporting In Albania, 2017.

[16] Parrella, A., Mayer, A., Gold, M., Marshall, H., Baghurst, P. (2013). Healthcare Providers' Knowledge, Experience And Challenges Of Reporting Adverse Events Following
Immunisation: A Qualitative Study. Biomed Central 13, 313-325.

[17] Fadare, J., Okenzie, E., Afolabi, A., Baz C., Musa, A. (2011). Knowledge, Attitude And Practice Of Adverse Drug Reaction Reporting Among Healthcare Workers In A Tertiary Centre In Northern Nigeria. Tropical Journal of Pharmaceutical Research, 10(3), 235.

Citation: Aron Rezene, et al, Knowledge, Perception, and Barriers of Reporting of Nurses on Surveillance of Adverse Events Following Immunization in Zobamaekel, Eritrea. ARC Journal of Public Health and Community Medicine.2019; 4(3):1-12. DOI: dx.doi. org/10.20431/2456-0596.0403001.

Copyright: (c) 2019 Authors. This is an open-access article distributed under the terms of the Creative Commons Attribution License, which permits unrestricted use, distribution, and reproduction in any medium, provided the original author and source are credited. 